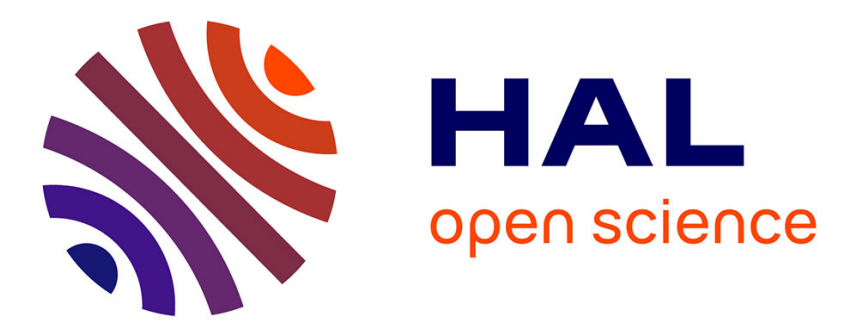

\title{
Towards the modelling of a heat-exchanger reactor by a dynamic approach
}

Juan Carlos Marin Gallego, Nelly Olivier-Maget, Gilles Hetreux, Nadine Gabas, Michel Cabassud

\section{- To cite this version:}

Juan Carlos Marin Gallego, Nelly Olivier-Maget, Gilles Hetreux, Nadine Gabas, Michel Cabassud. Towards the modelling of a heat-exchanger reactor by a dynamic approach. Canadian Journal of Chemical Engineering, 2015, vol. 93 ( ${ }^{\circ}$ 2), pp. 451-464. 10.1002/cjce.22119 . hal-01345756

\section{HAL Id: hal-01345756 https://hal.science/hal-01345756}

Submitted on 15 Jul 2016

HAL is a multi-disciplinary open access archive for the deposit and dissemination of scientific research documents, whether they are published or not. The documents may come from teaching and research institutions in France or abroad, or from public or private research centers.
L'archive ouverte pluridisciplinaire HAL, est destinée au dépôt et à la diffusion de documents scientifiques de niveau recherche, publiés ou non, émanant des établissements d'enseignement et de recherche français ou étrangers, des laboratoires publics ou privés. 


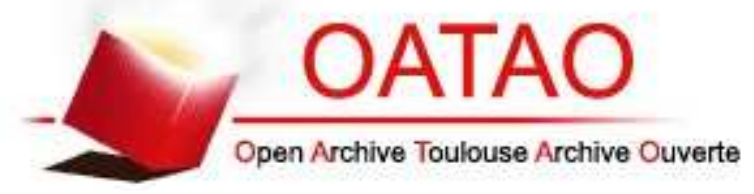

\section{Open Archive TOULOUSE Archive Ouverte (OATAO)}

OATAO is an open access repository that collects the work of Toulouse researchers and makes it freely available over the web where possible.

This is an author-deposited version published in : http://oatao.univ-toulouse.fr/ Eprints ID : 15981

To link to this article : DOI : 10.1002/cjce.22119

URL : http://dx.doi.org/10.1002/cjce.22119

To cite this version : Marin Gallego, Juan Carlos and Olivier-Maget, Nelly and Hétreux, Gilles and Gabas, Nadine and Cabassud, Michel Towards the modelling of a heat-exchanger reactor by a dynamic approach. (2015) The Canadian Journal of Chemical Engineering, vol. 93 ( $\left.\mathrm{n}^{\circ} 2\right)$. pp. 451-464. ISSN 0008-4034

Any correspondence concerning this service should be sent to the repository administrator: staff-oatao@ listes-diff.inp-toulouse.fr 


\title{
TOWARDS THE MODELLING OF A HEAT-EXCHANGER REACTOR BY A DYNAMIC APPROACH
}

\author{
Marin Gallego Juan Carlos, ${ }^{*}$ Olivier-Maget Nelly, Hetreux Gilles, Gabas Nadine and Cabassud Michel \\ Laboratoire de Génie Chimique. UMR-5503 (INPT/CNRS/UPS). 4, Allée Emile Monso, BP 84234 F-31432, Toulouse, France
}

The aim of this paper is to present the development of a simulation tool in order to assess the inherently safe characteristics of a heat-exchanger reactor (HEX) operating reaction systems. The modelling of steady and transient states of a HEX reactor is performed following a hybrid dynamic approach. The global dynamic behaviour of this reactor can be represented by several continuous models, which are bounded by state or time events. Each continuous model is defined as a system of partial differential-algebraic equations. The numerical scheme is based on the method of lines. Special attention is paid to the model initialization and a simulation strategy of the start-up phase is presented. The validation of the model is made by numerous examples, such as the simulation of an exothermic reaction.

Keywords: Dynamic Hybrid Simulation, axial dispersion model, method of lines, heat-exchanger reactor

\section{INTRODUCTION}

$\mathrm{D}$ uring the last decades, advances in reactor design have made possible to transpose traditional batch chemical processes to continuous intensified systems. As a matter of fact, discontinuous reactors present technological limitations that may result in safety and productivity constraints. These drawbacks are mainly due to their poor heat exchanging performances. In process intensification, heat-exchanger reactors (HEX reactors) are well-known for their thermal and hydrodynamic performances ${ }^{[1]}$ and are well-suited for highly exothermic reactions. ${ }^{[2]}$

The application of HEX reactors for multiphase reactions is a subject of interest in process safety. Even though the use of this type of processes is an interesting alternative to batch systems, the number of parameters to take into account for their design (system kinetics, hydrodynamics, heat and mass transfer data and multiple channel configurations) makes difficult their application to multiphase systems. In this context, dynamic simulation is a useful tool to study the system from a process safety point of view and to analyze the influence of the different operating parameters.

In this paper, we focus on the first steps of the modelling of intensified HEX reactors for multiphase systems. Chemical reactions in multiphase systems lead to highly non-linear problems. Some dynamic models for homogeneous systems are studied in literature. ${ }^{[2,3]}$ Recent studies on steady state modelling for multiphase applications have been proven useful for the design of HEX reactors. ${ }^{[4]}$ However, studying the system dynamics is an essential step towards a complete understanding of any new equipment in terms of process safety. ${ }^{[5,6]}$

The main objective of this study is to validate the hydrodynamic and thermal model of the HEX reactor. This work is then organized as follows. In the section "Reactor Model", a brief description of the reactor is made and the model equations are written. In the section "Resolution Methods", the model structure is presented and the applied numerical resolution strategy is discussed. The hybrid dynamic approach is then explained via the simulation of the startup of the reactor in the section "Dynamic Hybrid Simulation". In the section "Simulation Results", some preliminary results for the validation of hydrodynamics equations are presented and dis- cussed. Firstly, the simulation of the start-up and the filling of the reactor illustrates the hybrid approach. Next, the hydrodynamic model is validated thanks to

- the simulation of a residence time distribution experiment and the comparison of the results with experimental data;

- the simulation of a change of the properties of the inlet fluid.

Then, the thermal part of the model is studied through the simulation of three examples: heating by the wall at constant temperature, an exothermic system with an adiabatic behaviour and an exothermic reaction with heat exchange with a wall at constant temperature.

Finally, "Conclusion and Perspectives" presents some conclusions and perspectives.

\section{REACTOR MODEL}

\section{General Description of the Reactor}

Designed with a plate heat exchanger modular structure, HEX reactors are available following a wide variety of configurations. ${ }^{[1]}$ Reaction and cooling plates are separated by a thermal-conducting plate. The number of plates and the geometric configuration are chosen according to mixing and thermal requirements, fluid properties, reaction parameters and safety considerations. Process and utility flows are mostly circulating perpendicularly. For simulation purpose, it is only possible to define co-current or counter-current flow between two contiguous plates by considering the main flow direction of each channel. To completely define the flow in a reacting channel, three spatial coordinates would be needed.

* Author to whom correspondence may be addressed.

E-mail address: juancarlos.maringallego@inp-toulouse.fr

DOI $10.1002 /$ cjce.22119 


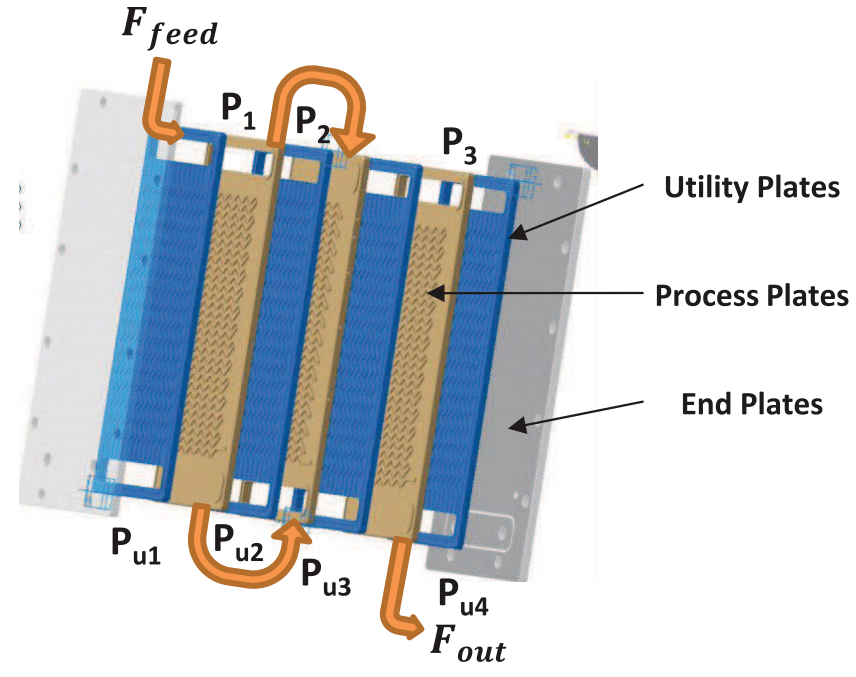

Figure 1. Channel and flow configuration. ${ }^{[7]}$

Figure 1 shows one possible flow configuration for the reacting plates. The utility flow presents a Z-type arrangement and the process flow circulates in a single channel in order to offer the highest possible residence time for reactants. $\mathrm{N}_{\mathrm{p}}$ is the total number of plates and $\mathrm{P}_{1}, \mathrm{P}_{2}, \ldots \mathrm{P}_{\mathrm{Np}}$ are relative to the Np plates. $\mathrm{F}_{\text {feed }}$ and $\mathrm{F}_{\text {out }}$ represent the inlet and outlet flow rate respectively.

Moreover, the utility flow rate is widely superior to the process flow rate. This fact implies that the different geometric configurations of the utility flow can be neglected for the evaluation of the thermal transfer.

\section{Model Equations}

Even if the flow structure within the channel has a threedimensional nature, classical models in chemical reaction engineering admit geometrical simplifications. Mass and heat balances within the reactor are written as a system of Partial Differential and Algebraic Equations (PDAE) in one dimension. HEX reactor hydrodynamics has been characterized during the last decade and previous studies show that the single phase flow is well represented by the axially dispersed plug-flow reactor model. ${ }^{[1,8,7]}$

\section{Hydrodynamic Model}

For multiphase flow, a simplified one-dimensional flow model has been developed. As the homogeneous axially dispersed plug flow model, it takes into account the axial dispersion effects in continuous phases via a dispersion term. Consider one fluid phase $\alpha$, flowing throughout the channel length. Let $\mathrm{z}$ be the spatial coordinate, followed by the mean flow. The partial molar balance of a component $k$ within this phase presenting axial dispersion is written as follows.

$\frac{\partial}{\partial t}\left(\varepsilon^{\alpha} x_{k}^{\alpha} C^{\alpha}\right)=\frac{\partial}{\partial z}\left(D_{a x} \alpha \frac{\partial\left(\varepsilon^{\alpha} x_{k}^{\alpha} C^{\alpha}\right)}{\partial z}\right)-\frac{\partial}{\partial z}\left(\varepsilon^{\alpha} x_{k}^{\alpha} C^{\alpha} u^{\alpha}\right)+H_{M_{k}}^{\alpha}+Q_{M_{k}}^{\alpha}$.

At any point within the reactor, the time rate change of the molar concentration depends on four terms given by the right-hand side of Equation (1):

- a molar diffusion flux,

- a convective flux,
- a source term for chemical reactions within the phase $\alpha$, calculated as

$$
\mathscr{H}_{M_{k}}^{\alpha}=\sum_{r=1}^{N_{r}^{\alpha}} v_{k, r} R_{r}^{\alpha}
$$

- a source term representing mass transfer between phases, given by

$$
\mathcal{Q}_{M_{k}}^{\alpha}=\sum_{\gamma=1 \neq \alpha}^{N \phi} Q_{k}^{(\gamma \alpha)}
$$

The velocity is calculated thanks to this equation:

$u^{\alpha}=\frac{W^{\alpha}}{\Omega \varepsilon^{\alpha} C^{\alpha} \bar{M}^{\alpha}}$.

The phase fraction and the phase velocity are two variables intrinsically related. The complexity of the multiphase interactions makes mandatory the acquisition of some experimental observation and data to feed a macroscopic one-dimensional model. The phase velocity and the phase volume fraction are implicitly computed with the phase material balance, and, in order to complete the PDAE system, specific constraints on phase volume fractions are needed. These constraints depend on the actual multiphase flow regime. We can assume as a first approximation that all phases flow at the same velocity, as in slug flow regime.

The phase material balance is given by the following equation:

$$
\frac{\partial}{\partial t}\left(\varepsilon^{\alpha} C^{\alpha}\right)=\frac{\partial}{\partial z}\left(D_{a x} \alpha \frac{\partial\left(\varepsilon^{\alpha} C^{\alpha}\right)}{\partial z}\right)-\frac{\partial}{\partial z}\left(\varepsilon^{\alpha} C^{\alpha} u^{\alpha}\right)+\sum_{k} H_{M_{k}}^{\alpha}+\sum_{k} Q_{M_{k}}^{\alpha} .
$$

A constraint on the phase volume fraction is given by

$$
1=\sum_{\alpha=1}^{N_{\varphi}} \varepsilon^{\alpha}
$$

\section{Thermal Model}

Temperature gradients between phases can be neglected. The influence of the friction loss on the energy balance is neglected. As usually done in chemical reactor modelling, we can assume an isobaric system. The energy balance is given by

$\frac{\partial}{\partial t}\left(\sum_{\alpha} \varepsilon^{\alpha} C^{\alpha} h^{\alpha}\right)=\frac{\partial}{\partial z}\left(\lambda_{a x} \alpha \frac{\partial T}{\partial z}\right)-\frac{\partial}{\partial z}\left(\sum_{\alpha} \varepsilon^{\alpha} C^{\alpha} h^{\alpha} u^{\alpha}\right)+\mathscr{H}_{T}+\mathcal{Q}_{T}$.

$\mathscr{H}_{\mathrm{T}}$ is a source term representing heat production due to chemical reactions:

$\mathscr{H}_{T} \sum_{r} R_{r}^{\alpha} \Delta H_{r}$

$Q_{T}$ represents the heat transfer between the fluid and the reactor wall:

$Q_{T}=U \alpha\left(T-T_{w}\right)$. 
As for most applications, enthalpy dependences on the pressure and chemical potentials are negligible. For an isobaric system, enthalpy for each phase is then calculated as follows:

$h^{\alpha}(T)=h_{\text {ref }}+\int_{T_{\text {ref }}}^{\theta} C p^{\alpha} d \theta$.

\section{Boundary Conditions}

Boundary conditions applied to the first and last cells of a reacting plate of length L are defined in Table 1. Each boundary can either be opened or closed to dispersion. In our case, an opened boundary is defined to link reaction plates. Closed boundaries are applied to the inlet and outlet of the reactor.

Some constitutive equations for the calculation of physical properties such specific heat, thermal conductivity, and other model parameters such as the axial dispersion coefficient, and the heat transfer coefficient are also included in the PDAE system.

\section{RESOLUTION METHODS}

The hybrid dynamic model has been developed in MATLAB. For the partial differential Equations (1) and (5), the chosen resolution scheme is derived by applying the method of lines. ${ }^{\left[{ }^{[9]}\right.}$ This method proceeds in two main steps. Spatial derivatives are first approximated using a discretization method (finite differences, finite volumes, or finite elements). The resulting system of semi-discrete (discrete in space and continuous in time) equations can be integrated in time using one of the Ordinary Differential Equations (ODE) solvers from MATLAB. A suitable solver for stiff odes, ode15s, has been used in this work. Ode15s is a variable order solver based on the numerical differentiation formulae (NDF), which are a variant of backward differentiation formulae (BDFs or Gear's method)..$^{[10,11]}$

The finite volume method has been used as it is conservative from construction for the modelling of the hybrid system. The choice of a conservative scheme is an essential step towards the achievement of a generic cell model. In order to illustrate these aspects, the start-up and the filling of the reactor are simulated. Then, the finite difference method is used for the simulation of the hydrodynamic, thermal and reactive behaviour of the reactor.

\section{Finite Difference Approximation}

The semi-discrete equations are obtained by replacing derivative terms in Equations (1) and (3) by a convenient choice of finite

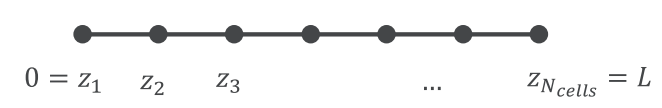

Figure 2. Finite difference grid.

difference approximation. Figure 2 represents the regular grid of the finite difference used in this work.

As presented by Vande Wouwer et al., ${ }^{[12]}$ differentiation matrixes can be used for computing derivative approximations. This operation is done straightforward by multiplying vector values by the matrix corresponding to the chosen approximation. Special attention should be given to the numerical stability of the resulting scheme.

Detailed information on its implementation and stability is available in literature. ${ }^{[13,14]}$

Consider the homogeneous version of Equation (1) with constant $D_{a x}$. When using an upwind first order approximation for the first order derivative and a second order centred approximation for the second order derivative, the resulting discretized scheme for Equation (1) is given as follows:

$$
\begin{aligned}
\frac{\partial x_{i} C_{i}}{\partial t}= & D_{a x}\left(x_{i} \frac{C_{i+1}-2 C_{i}+C_{i-1}}{\Delta z^{2}}+2\left(\frac{C_{i}-C_{i-1}}{\Delta z}\right)\right. \\
& \left.\times\left(\frac{x_{k, i}-x_{k, i-1}}{\Delta z}\right)+C_{i} \frac{x_{i+1}-2 x_{i}+x_{i-1}}{\Delta z^{2}}\right) \\
& -\left(u_{i} C_{i} \frac{x_{k, i}-x_{k, i-1}}{\Delta z}+u_{i} x_{k, i} \frac{C_{i}-C_{i-1}}{\Delta z}+C_{i} x_{k, i} \frac{u_{i}-u_{i-1}}{\Delta z}\right)+H_{M}
\end{aligned}
$$

\section{Finite Volume Semi-Discretization}

Figure 3 illustrates the structure of the model. In this case the physical system corresponds to a reacting plate with meandering squared channels, as studied by Anxionnaz et al. ${ }^{[15]}$ The channel is etched inside the conducting material. By following a finite volume approach, the reacting channel can be discretized into $N$ unitary cells, which are placed in such a way that they represent the configuration of the actual system. The inlet flow rate is $F_{\text {feed }}$ and the outlet flow rate corresponding to the flow leaving the last discretization cell is $F_{\text {out }}$. Each cell is able to transfer mass and heat with other neighboring cells. Interactions of the $\mathrm{i}^{\text {th }}$ cell are considered only with the cells that share a boundary surface. Mass fluxes are exchanged by two sides, while thermal fluxes can be exchanged by the 6 sides of the cell.

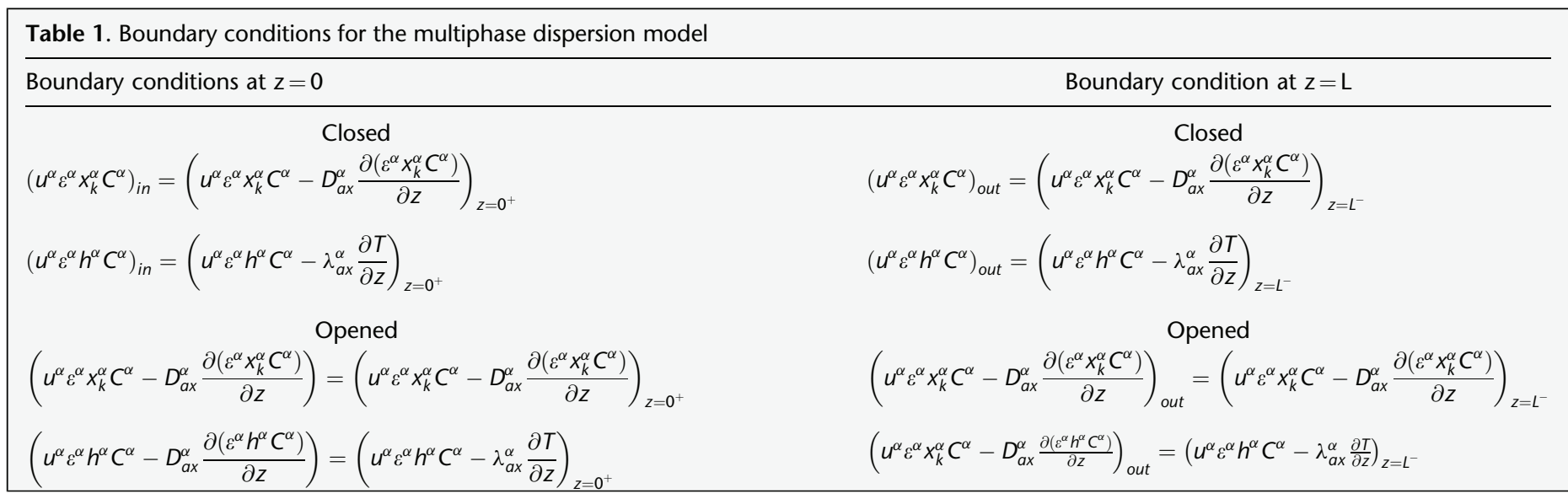



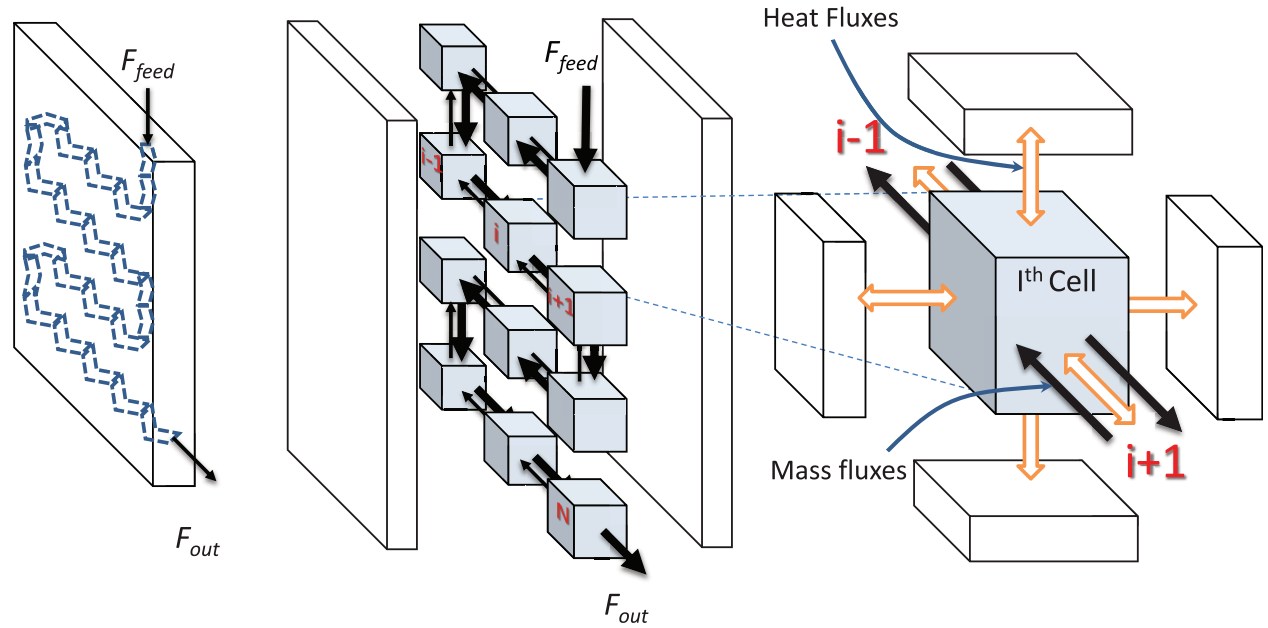

Figure 3. Geometric structure and discretization of a single reacting plate.

The integral forms of Equations (1) and (5) result in the following expressions:

$V \frac{\partial}{\partial t}\left(\varepsilon_{i}^{\alpha} C_{i}^{\alpha} x_{k, i}^{\alpha}\right)=-\Omega\left(f_{M_{k, i+\frac{1}{2}}^{\alpha}}^{\alpha}-f_{M_{k, i-\frac{1}{2}}}^{\alpha}\right)+V\left(\mathscr{H}_{M_{k, i}}^{\alpha}+\mathcal{Q}_{M_{k, i}}^{\alpha}\right)$

$V \frac{\partial}{\partial t}\left(\sum_{\alpha} \varepsilon^{\alpha} C^{a} h^{\alpha}\right)=-\Omega\left(\sum_{\alpha} f_{T_{i+\frac{1}{2}}}^{\alpha}-\sum_{\alpha} f_{T_{i-\frac{1}{2}}}^{\alpha}\right)+V\left(\mathscr{H}_{T i}+\mathcal{Q}_{T i}\right)$

$f$ terms are defined as numerical fluxes crossing the control volume boundaries. Notice that the first term of right-hand sides of Equations (8) and (9) can be regarded as finite difference approximations of diffusive and dispersive terms in Equations (1) and (3).

The intercell fluxes can take two forms. The purely convective fluxes represent the ideal plug-flow feature of the reactor and are written as

$f_{M_{k, i}}^{\alpha}=u_{i}^{\alpha} \varepsilon_{i}^{\alpha} C_{i}^{\alpha} x_{k, i}^{\alpha}$

$f_{T_{i}}^{\alpha}=u_{i}^{\alpha} \varepsilon_{i}^{\alpha} C_{i}^{\alpha} h_{i}^{\alpha}$

whereas convective-dispersive fluxes takes into account the axial dispersion of the flow. Fluxes for material and heat balances are respectively given by

$f_{M_{k, i}}^{\alpha}=u_{i}^{\alpha} \varepsilon_{i}^{\alpha} C_{i}^{\alpha} x_{k, i}^{\alpha}-D_{a x, i}^{\alpha}\left(\frac{\partial\left(\varepsilon_{i}^{\alpha} C_{i}^{\alpha} x_{k, i}^{\alpha}\right)}{\delta z}\right)$

$f_{T_{i}}^{\alpha}=u_{i}^{\alpha} \varepsilon_{i}^{\alpha} C_{i}^{\alpha} h_{i}^{\alpha}-\lambda_{a x, i}^{\alpha}\left(\frac{\partial T_{i}}{\partial z}\right)$

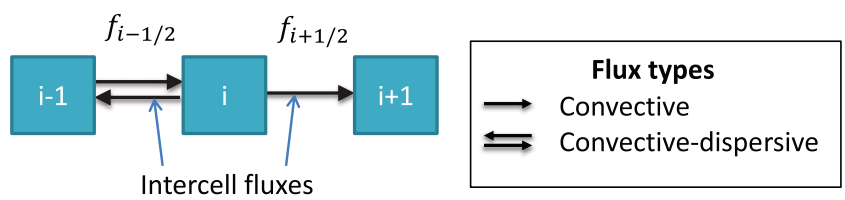

Figure 4. Definition of intercell fluxes.
For the following sections, the chosen representation of these fluxes is shown in Figure 4.

As previously mentioned, the reactor presents a modular structure. It is composed of plates, and plates are composed of elementary cells (Figure 3). The properties of each cell are determined by heat and mass conservation; however, the cell model structure may not be the same for inner and boundary cells according to the chosen numerical scheme. In addition, the approximation method for $f_{i+1 / 2}$ may result in a different flux definition for the two consecutive cells ( $i$ and $i+1)$.

Consider that the fluid is flowing from left to right. The first order upwind estimation for the intercell fluxes has been chosen despite its numerical dissipation as it has the advantage of being unconditionally stable in the presence of steep fronts. ${ }^{[13]}$ A second order centred finite difference approximation is chosen to calculate the derivative term for dispersion.

$f_{M_{k, i-\frac{1}{2}}}^{\alpha}=u_{i-1}^{\alpha} \varepsilon_{i-1}^{\alpha} C_{i-1}^{\alpha} x_{i-1}^{\alpha}-D_{a x, i-1}^{\alpha}\left(\frac{\varepsilon_{i}^{\alpha} C_{i}^{\alpha} x_{k, i}^{\alpha}-\varepsilon_{i-1}^{\alpha} C_{i-1}^{\alpha} x_{k, i-1}^{\alpha}}{\Delta z}\right)$

As for the first and last fluxes, the approximation is staggered in order to keep the same order of accuracy.

Thanks to the conservative finite volume semi-discretization, it is possible to adopt one single equation for different cell models. A generic multiphase model is then given by

$$
\begin{gathered}
V \frac{\partial}{\partial t}\left(\beta_{i} \varepsilon_{i}^{\alpha} C_{i}^{\alpha} x_{k, i}^{\alpha}\right)=\Omega\left(f_{M, \text { in }_{k, i}}^{\alpha}-f_{M, \text { out }_{k, i}}^{\alpha}\right)+V \beta_{i}\left(\mathscr{H}_{M_{k, i}}^{\alpha}+\mathcal{Q}_{M_{k, i}}^{\alpha}\right) \\
\begin{aligned}
V \frac{\partial}{\partial t}\left(\beta_{i} \sum_{\alpha} \varepsilon^{\alpha} C^{a} h^{\alpha}\right)= & -\Omega\left(\sum_{\alpha} f_{T, \text { in }}{ }^{\alpha}-\sum_{\alpha} f_{T, \text { out }}{ }^{\alpha}\right) \\
& +V \beta_{i}\left(\mathscr{H}_{T_{i}}+\mathcal{Q}_{T_{i}}\right)
\end{aligned}
\end{gathered}
$$

The variables $f_{M, n_{k, i}}^{\alpha}$ and $f_{M, o u t_{k . i}}^{\alpha}$ are molar fluxes of a component $k$ that goes from and to the $\mathrm{i}^{\mathrm{th}}$ cell, respectively. $f_{T, \text { in }}^{\alpha}$ and $f_{t, \text { out }}^{\alpha}$ are the thermal fluxes entering and leaving the $\mathrm{i}^{\text {th }}$ cell. Here, $\beta_{i}$ is the fraction of the total volume occupied by the fluid phases in the ith control volume. $\beta_{i}$ is the same for all the phases and is equal to one once the cell is full. This state variable has been introduced to take 


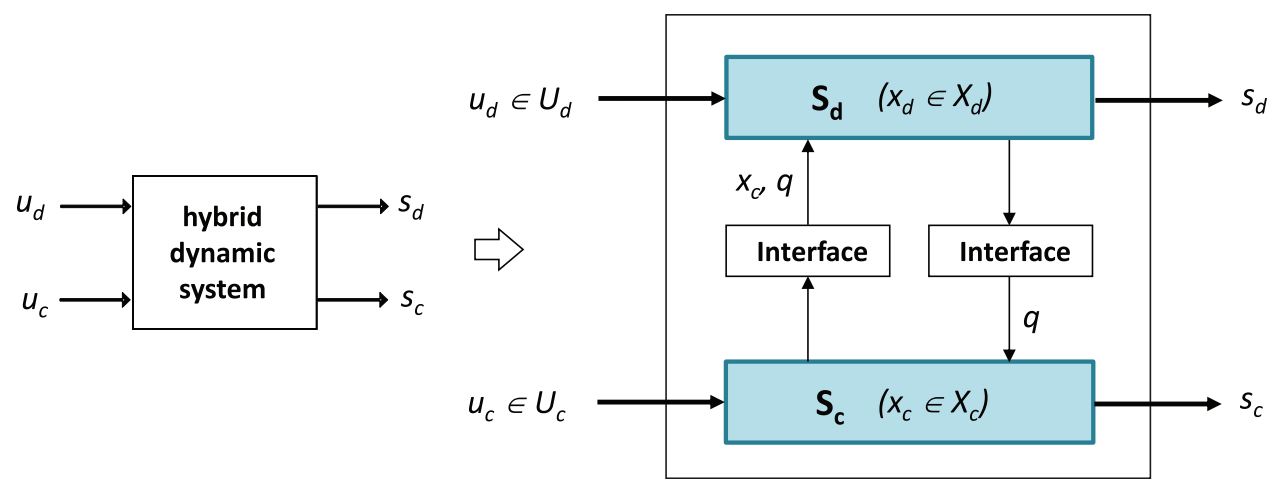

Figure 5. Hybrid dynamic system.

into account the representation of empty or partially filled cells with the same model. The global model can be modified by exclusively changing the flux definition at each state.

\section{DYNAMIC HYBRID SIMULATION}

The continuous equations described previously correspond to the modelling of the "max" state of a cell (i.e., the state where all fluxes and fluid phases exist). In our case, the state vector corresponds to the max state of our system. Nevertheless, the model structure changes according to the discrete aspects. For this reason, this section presents the hybrid dynamic aspects of the model.

\section{General Aspects}

The objective is to study the HEX reactor in steady state but also in various transient states (start-up, shutdown, response to a disturbance, etc). In this context, a "hybrid dynamic model" of the system has to be established (Figure 5). In a general manner, this approach leads to make a discrete model $S_{d}$ interact with a piecewise continuous or discontinuous model $S_{c}$.

In our case, the hybrid model of the system is formalized by Object Differential Petri Net (ODPN). ${ }^{[16]}$ When a hybrid dynamic system evolves, it passes through different configurations $q$, also called discrete state $x_{d}$ (or modes) of the system. Each configuration $q$ is identified by a place $\mathbf{p}_{\mathbf{q}}$. If the continuous state variables $X_{q}$ must evolve in this configuration, then a differential place $\mathbf{p}_{\mathbf{q}}$ identifies this configuration $q$ and a differential and algebraic equations (DAE) system $\boldsymbol{F}_{\boldsymbol{q}}$ is associated with it. In consequence, the evolution of the continuous variables $X_{c}$ of the system is driven by a piecewise continuous model while the discrete part realizes the management of the legal sequences of switching between the continuous sub-models. Each continuous sub-model is then a specific configuration of the Equations (1) to (2). In order to detect a change in system $S$, state events or temporal events determine the crossing of each transition $\mathbf{t}_{\mathbf{i}}$. An event is usually materialized by an algebraic equation function noted $e_{i}$. It is monitored as soon as all previous places of the transition $\mathbf{t}_{\mathbf{i}}$ are marked and it is considered as an additional condition to the firing of the transition $\mathbf{t}_{\mathbf{i}}$. When crossing the transition $\mathbf{t}_{\mathbf{i}}$, actions can be executed. Action, called $j_{i}$, allows, for example, calculating the initial values of continuous states and their time derivatives, in accordance with the following configuration. Figure 6 illustrates the evolution rules of this kind of Petri Net, applied to a system of differential and algebraic equations.

From a topological point of view, a complex system such as batch or continuous processes must be decomposed hierarchically into several entities (Figure 7). At the first topological level, the control part (the controller) and the operative part (the process) are clearly distinguished. The controller is modelled by a Petri net describing the recipe that the process must follow. This recipe is defined by continuous values (quantities of reactants, operating conditions, etc.) and generates the events that drive the simulation of the operative part.
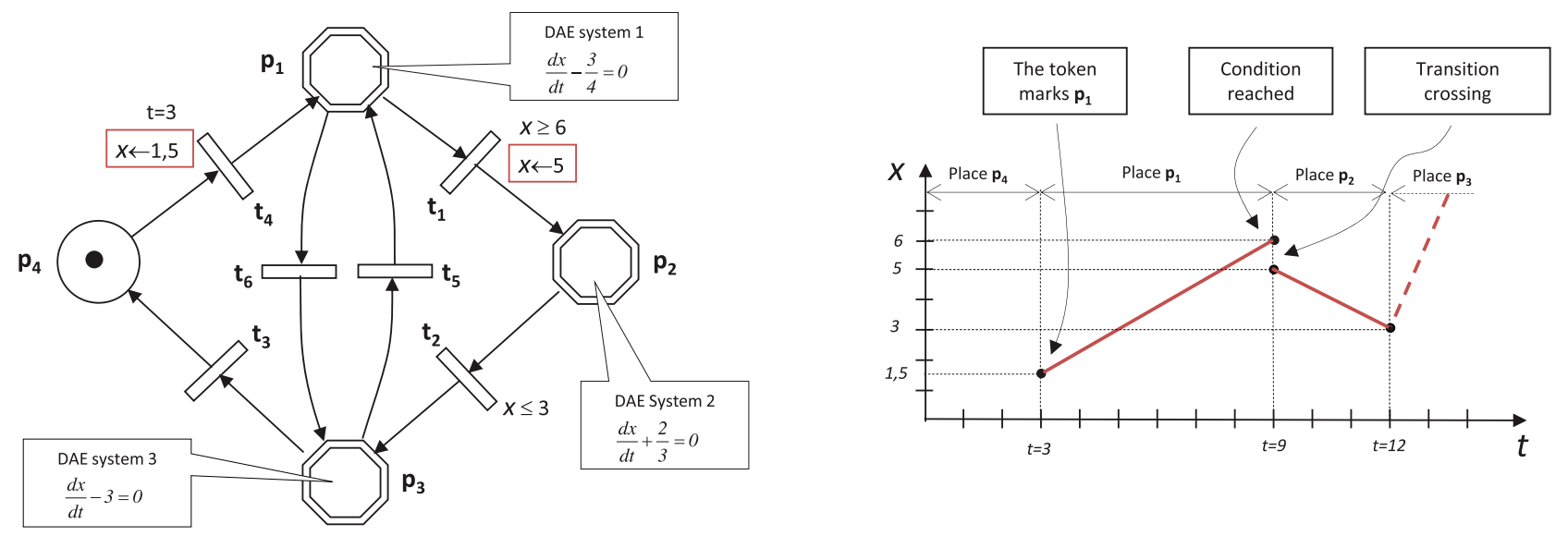

Figure 6. Example of Petri net representing the evolution of hybrid dynamic system. 


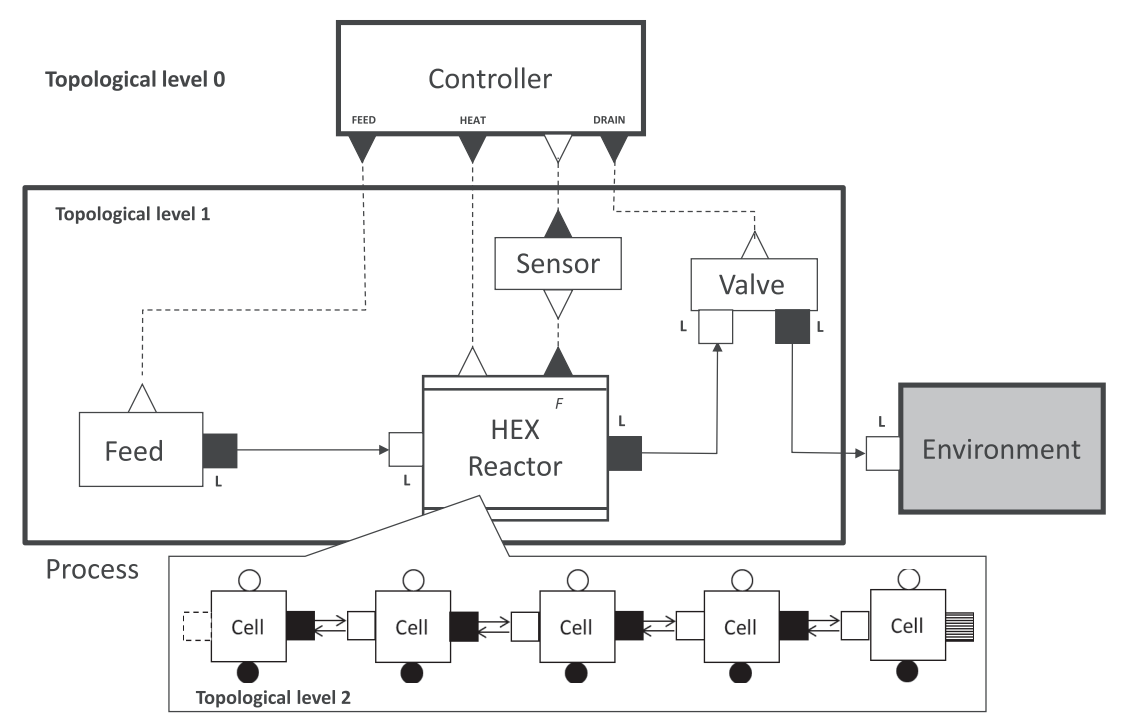

Figure 7. Hierarchical decomposition of the system.

Concerning the modelling of the operative part, the ODPN can be structured in different ways. It depends essentially on the nature of the study to achieve and the topological level considered. In this framework, one or more Petri Nets are developed in order to represent the phenomenological evolution of the system. In particular, they include the heat and mass transfer mechanisms that are specific to the operation steps, the evolution of the phase system as well as main and secondary reaction kinetics. In this article, we restrict the study to the start-up phase and filling of the HEX reactor.

\section{The Start-Up and Filling Phase}

The start-up transient simulation is a critical aspect in dynamic modelling, simulation and control. The risk of incidents is higher during start-up than in steady state operation. Previous studies on control of HEX reactors for exothermic homogeneous systems highlight that a dynamic hybrid approach allows a robust control of start-up for safety purposes. ${ }^{[17,18]}$

Two strategies can be implemented for the dynamic simulation of this phase. If each variable in the state vector has a physical meaning, for any state of the system, then it is possible to build a complete model from the beginning of the simulation and to reduce the impact of the hybrid features. The second strategy corresponds to a progressive construction of the model. The importance of this phase relies on the fact that all variables are initialized. The more the system is complex the more difficult is the research of a coherent initial state. Hybrid dynamic modelling allows a staged management of the transitions, including an initialization of each sub-model. ${ }^{[19]}$ In this study, the second strategy is adopted.

According to the process, an empty reactor is a reactor filled with an inert stagnant fluid phase, which is mostly gaseous $\mathrm{N}_{2}$ or air. Filling a reacting plate with a liquid phase is a multiphase process and the shape of the transient fluid-fluid interface evolves in a complex manner. A qualitative representation of this evolution is the subject of computational fluid dynamics studies, which require multidimensional spatial grids and imply higher computational burden. Such a detailed description is not part of the scope of this work. The one-dimensional model presented in the previous sections takes into account flow phenomena by integrating macroscopic parameters (axial dispersion coefficient, heat and mass transfer coefficients, explicit dispersed phase velocity/ volume fraction equations). The evolving interface is modelled by integrating a void fraction parameter.

For the simulation of the filling of the reactor, several hypotheses can be considered:

- The filling in the same time of all the cells of the reactor;

- The filling of a cell only when the previous one is full;

- And a mixed approach of the both previous cases.

In this work, the second hypothesis is considered, since the configuration and experimental conditions of our reactor justify its use.

\section{Global structure behaviour}

In order to illustrate the principles of the progressive construction of the model, consider the filling step of a reacting channel, which is discretized into 4 unitary cells. Figure 8 shows the Petri net that illustrates the evolution of the model for this case. Single arrows of cells represent convective fluxes and double arrows represent convective-diffusive fluxes.

At the initial state, the reacting channel is modelled as a series of empty cells. The thermodynamic variables that define the state and the properties of the reactants do not have a physical meaning as long as the reactor remains empty. Therefore, the heat and mass balances are excluded from the model before the introduction of reactants.

The progressive model construction begins right after the occurrence of an external event, such as the opening of an inlet valve, or the start-up of a pump. The transition $t_{M 1}$ contains the necessary conditions to switch to the next model. When transition $t_{M 1}$ is fired, its actions are performed. For this particular transition, the inlet flow of the reacting channel is equal to $F_{\text {feed }}$. The model equations for cell A change by considering an inlet flux, and new variables are properly initialized.

A token marks the first continuous place $\mathbf{M}_{1}$. Once cell A is filled, transition $t_{M_{2}}$ is fired and the convective flux between the first and second cell is instantiated. In the same way, the flux between the cells $B$ and $C$ is set to convective when the transition $t_{M 3}$ is fired.

Notice that the convective-dispersive flux from cell B to cell C is set at $t_{\mathbf{M} 4}$, after the third cell is filled. The derivative estimation of 


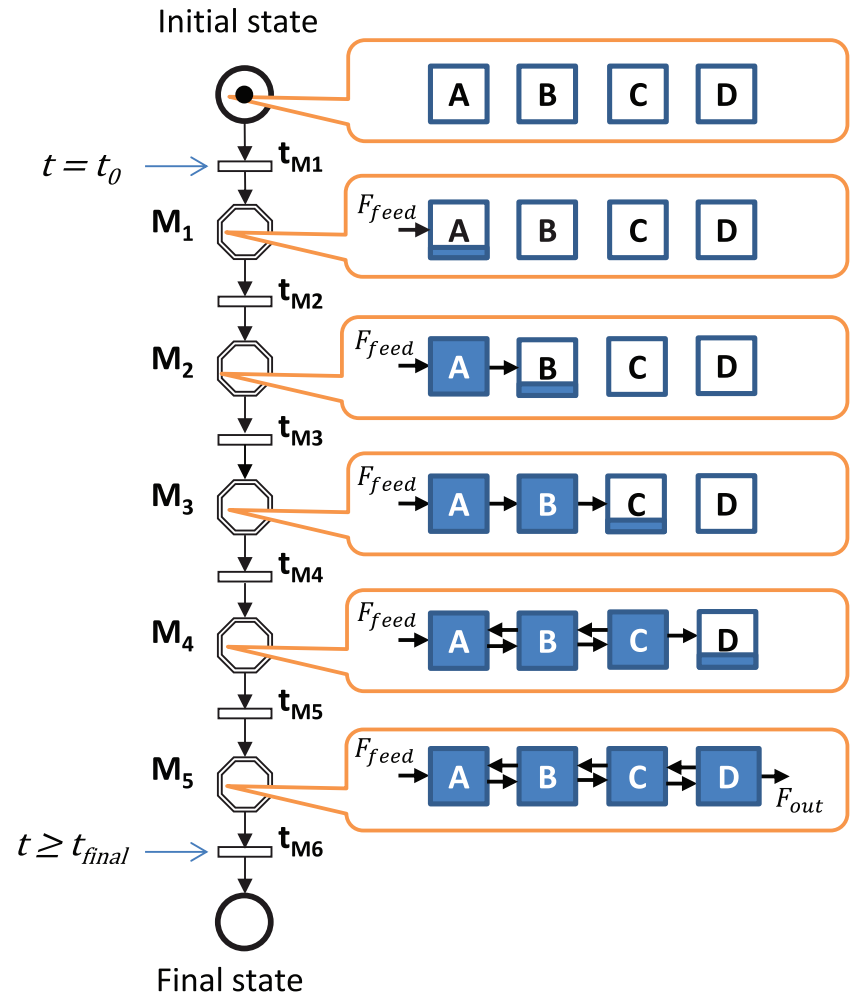

Figure 8. Petri net of the start-up step.

the dispersive flux term can be done if the variables for the first three cells are defined. The discrete model evolves throughout the time span. The final structure is achieved when the reacting channel reaches transition $\mathbf{t}_{\mathbf{M} 5}$ and the reactor is completely filled. During the marking of the continuous place $\mathbf{M}_{5}$, the simulation continues. The simulation ends when time is equal to $t_{\text {final }}$. This condition is the event of the transition $\mathbf{t}_{\mathbf{M G}}$.

\section{Unitary Cell behaviour}

Based on the global structure behaviour described in the previous sub-section, this Petri net formalism can be used to describe the behaviour of a single cell. This cell can take six different states considering the current values of $f_{\text {in }}$ and $f_{\text {out }}$. The different cell types are denoted using the nomenclature presented in Table 2 .

These cell types are described as follows:

- Empty Cell: This type represents the empty state of our cell. It is applied if three conditions are verified. The first condition is the absence of any molar hold-up (the cell is actually empty). Secondly, there is no flow or energy flux that crosses the cell boundaries. Thirdly, there are no sinks or sources considered. Consequently, it is unnecessary to apply the balance equations to the control volume, as any of the fluid variables have a physical meaning.

- Filling Cell: A partially filled cell with only one inlet flux is modelled as a single stirred tank reactor with one inlet flow. This state applies exclusively during the filling phase.

- Axially Dispersed Cell: The axially dispersed cell represents a control volume with two convective-dispersive fluxes crossing its boundaries. The dispersive part of a flux can be introduced once all the cells needed to the approximation of the fluxes are filled. This cell type corresponds to a discretized cell of the

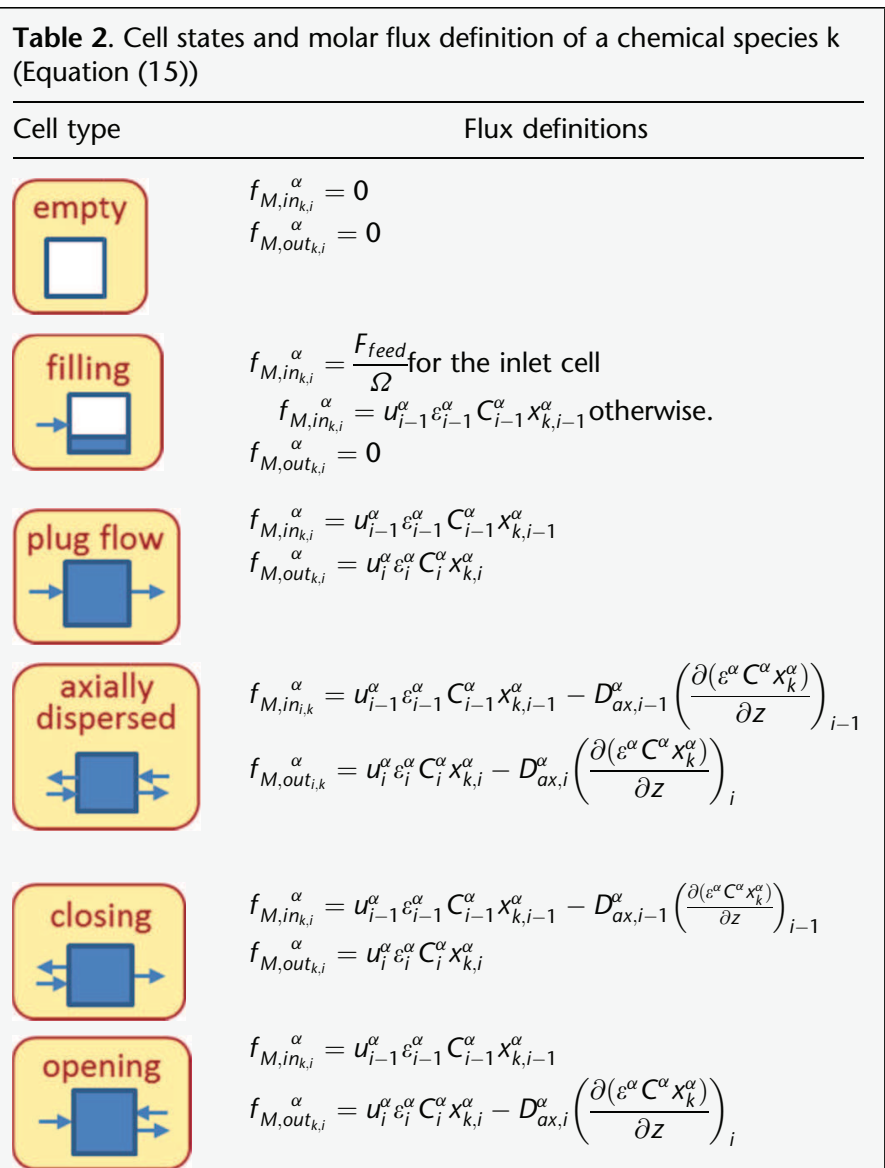

axial-dispersion model. The partial molar balance is given by Equation (1).

- Plug Flow Cell: In order to be able to apply the multiphase dispersion model (i.e., Equation (1)), the cells used for the approximation of the dispersive flux term (e.g., cells A, B and C for the approximation of the A-B flux) need to be already filled. When it is not the case, the dispersive term is neglected. The Plug Flow Cell represents this case. Only the convective part of the flux is considered. If this model is applied to each cell of the reactor, the overall model would correspond to the plug flow reactor model.

- Opening Cell: The flux entering the cell is convective-dispersive and the flux leaving is convective. The first non-filling cell of the series remains an opening cell if the reacting plate is closed to dispersion at the entry.

- Closing Cell: This cell state is achieved when the inlet flux is convective-dispersive and outlet is convective. It is used as a transition cell state between the plug flow and the axially dispersed cell model and translates the discontinuity of the flux. Typically, the first cell of a plate for which the boundary at the outlet is closed to dispersion is a closing cell.

The last two asymmetric cell types "closing" and "opening" are defined to implement the boundary conditions in Table 1, as well as to model the start-up phase of the HEX reactor for which the outlet boundary advances throughout the reacting channel.

The structural changes for each elementary cell can be extracted from Figure 8 . They can be represented by the cell Petri net in Figure 9. 


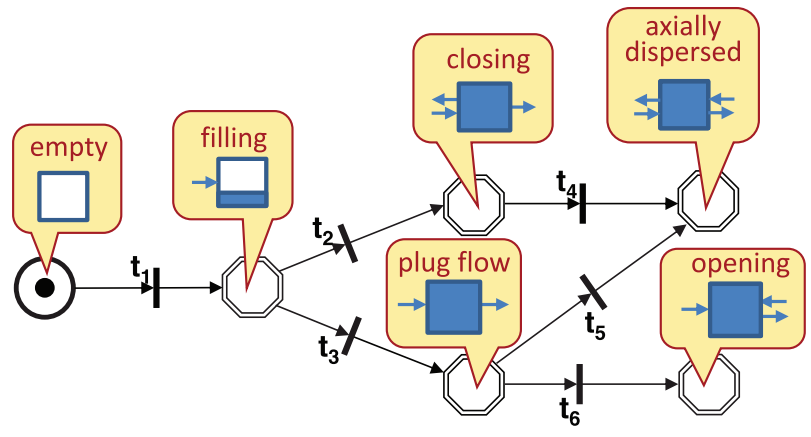

Figure 9. Petri net of the elementary cell.

The hybrid mathematical model is then initialized as a single filling cell. The cell travels through different states as the reactor structure evolves.

- In a general way, the transition $\mathbf{t}_{\mathbf{1}}$ initializes the cell model. If the previous cell of an empty cell is filled, a convective flux is created between the both of them. The first cell remains an exception since the condition to fire $t_{1}$ depends on an event that is independent of the reactor state variables, (i.e., pump start-up). The inlet flow of the first cell is set equal to $F_{\text {feed }}$.

- Transition $t_{2}$ is fired when the 3rd or higher filling cell is full. Two actions are performed. Firstly, the inlet flux is then convective-dispersive and secondly the outlet flux is convective.

- Transition $t_{3}$ is fired when the first or second cell is filled. The outlet flux is set to convective

- Transition $t_{4}$ is fired for a closing cell, if the cell next to it is filled. To transform the closing cell to an axially dispersed cell, $f_{\text {out }}$ is set to convective-dispersive.
- Transition $t_{5}$ is fired for the second cell when the third cell is filled. Both $f_{\text {in }}$ and $f_{\text {out }}$ are convective-dispersive fluxes.

- Transition $t_{6}$ is fired for the first cell if the second cell is filled and the outlet boundary is closed to dispersion. The outlet flux $f_{\text {out }}$ is thus convective-dispersive.

Then, consider the filling of a reactor composed of 4 elementary cells (Figure 8). Each elementary cell evolves thanks to the Petri net presented in Figure 9. Table 3 represents the state changes of the four cells A, B, C and D.

\section{SIMULATION EXAMPLES}

The complexity of the system requires a progressive method for the model validation. In this paper, the preliminary results of the HEX reactor simulations are presented. A homogeneous system is studied. Six examples are simulated. The first one (case 1) illustrates the hybrid dynamic approach presented in section 4 . It concerns the simulation of the start-up and the filling of the reactor. The next results allow the validation of the hydrodynamic and thermal parts of the model. The finite difference method is used for these simulations (cases 2 to 6 ). The hydrodynamic part of the model is validated thanks to the comparison of experimental and calculated residence time distributions (case 2). Moreover, the response of the model is analyzed when the composition of the inlet fluid is changed (case 3 ). Cases 4,5 , and 6 have been simulated to test the thermal part of the model. The first simulation (case 4) concerns the heating of a liquid with a wall of constant temperature. The second one (case 5) represents the performing of an exothermic reaction in an adiabatic reactor. In the last case, exothermic reaction is performed with heat exchange with constant wall temperature (case 6).

\section{Case 1: Start-up and Filling of the HEX Reactor}

For this section, let us consider a reacting plate with a total volume of $1.2 \times 10^{-5} \mathrm{~m}^{3}$. The case study parameters are presented in

Table 3. Individual cell Petri nets
Selated actions


Table 4. This reactor is fed with water at a flow rate, $F_{\text {feed }}$ of $10 \mathrm{~kg} \mathrm{~h}^{-1}$. The evolution of the filling rate for the first four cells is shown in Figure 10a.

For $N_{\text {cells }}=4$, the Petri net in Figure 8 describes the model evolution of the reacting channel. The filling of the cell A starts when transition $t_{0}$ is fired. Once the first cell is filled $\left(\beta_{A}=1\right)$, the transition $t_{1}$ is fired and the filling of cell $B$ starts. This behaviour is repeated for the following cells until the reactor is completely filled. This means that the filling rates of all cells are equal to one.

The channel mass hold-up is shown in Figure 10a. The axial dispersion coefficient is set to $1.310^{-3} \mathrm{~m}^{2} \mathrm{~s}^{-1}$. The mass hold-up increases to the maximum value of $12 \times 10^{-3} \mathrm{~kg}$ (Figure 10b). It corresponds to the total hold-up of the reactor. At $t=4.2 \mathrm{~s}$, the reactor is filled. For $N_{\text {cells }}=30$, the evolution of the filling rate along the reactor for the complete set of cells is shown in Figure 10c.

\section{Case 2: Residence Time Distribution}

Experimental data of residence time distributions for single phase systems on HEX reactors have been obtained in the framework of previous and on-going studies. ${ }^{[20]}$ The following experimental data has been obtained by using a Corning HEX reactor under the operating conditions listed in Table $5 .^{[21]}$

The model has been used to reproduce the system response with a Dirac-type concentration disturbance. Figure 11 shows experimental and simulated data for the outlet concentration of a tracer. The tracer is injected at $t=7.2 \mathrm{~s}$. The dispersion model is welladapted to represent the hydrodynamic behaviour of the reactor. A satisfactory representation is obtained with a $D_{a x}=1.1110^{-2} \mathrm{~m}^{2} \mathrm{~s}^{-1}$ or a Péclet number of $110\left(\mathrm{P}_{\mathrm{e}}=\mathrm{uL} / D_{a x}\right)$.
Table 4. Geometric and operation parameters for the filling of the reactor

\begin{tabular}{lcc}
\hline & Parameters & \\
\hline Reactor length & 3 & $\mathrm{~m}$ \\
Channel height & $2 \times 10^{-3}$ & $\mathrm{~m}$ \\
Channel width & $2 \times 10^{-3}$ & $\mathrm{~m}$ \\
Inlet flow rate & 10 & $\mathrm{~kg} \mathrm{~h}^{-1}$ \\
Density & 995 & $\mathrm{~kg} \mathrm{~m}^{-3}$ \\
\hline
\end{tabular}

\section{Case 3: Change of Inlet Fluid Composition}

A change of the composition of the feed is simulated: from pure water to pure ethanol. The same reactor as in case 1 is considered (Table 4). Table 6 lists the operating conditions.

For $t<2 \mathrm{~s}$, the HEX reactor is fed with water at a flow rate of $5.5 \mathrm{~kg} \mathrm{~h}^{-1}$. At $t=2 \mathrm{~s}$, water is completely changed by ethanol at the same temperature. The mass feed flow rate is kept constant. The composition change is not modelled by a perfect step signal. This step signal is smoothed to overcome the discontinuities of the model. Indeed, for DAE systems, discontinuities must be specially studied. ${ }^{[22]}$ Figure 12 shows the dynamic response of the system. Because of the change of fluid in the reactor inlet, all system variables change too. Then, for example the composition front evolves according to the velocity of the fluid and along the reactor (Figure 12a). The effect of the axial dispersion can be observed. Figure $12 \mathrm{~b}$ shows that the density has the same behaviour than those observed in Figure 12a. The evolution of the velocity is illustrated in Figure 12c. The change of fluid involves an increase of the velocity. At steady state, the velocity is still uniform in all cells.

(a)
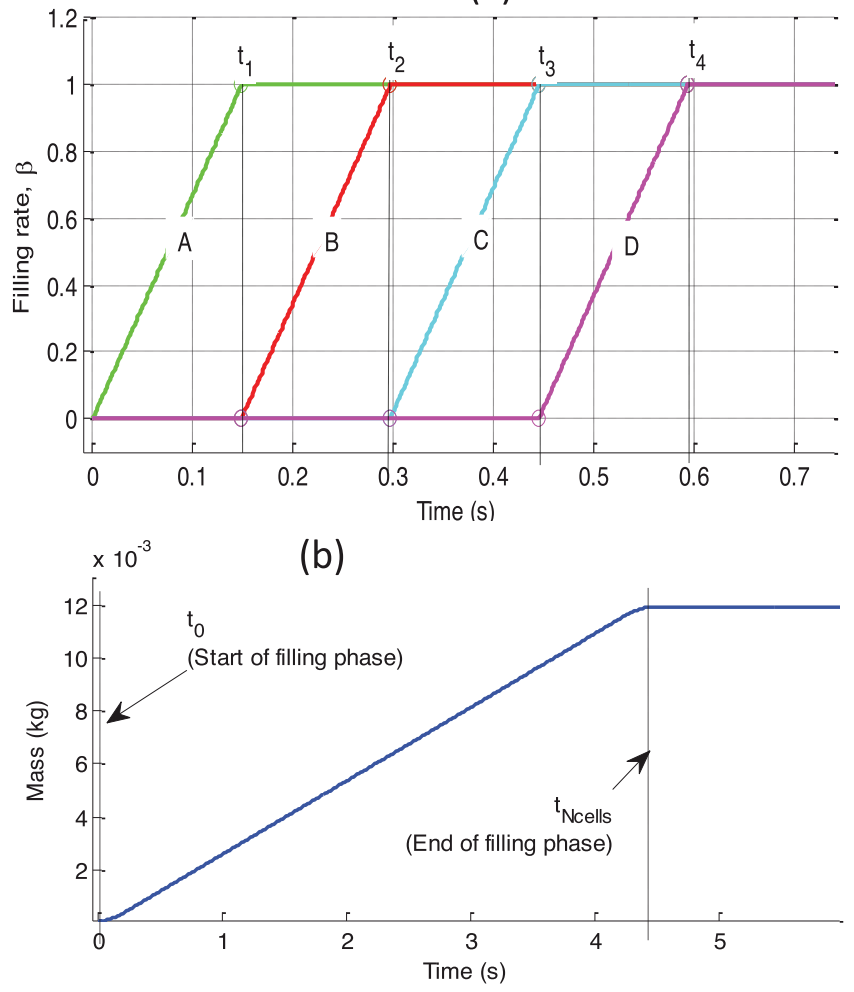

(c)

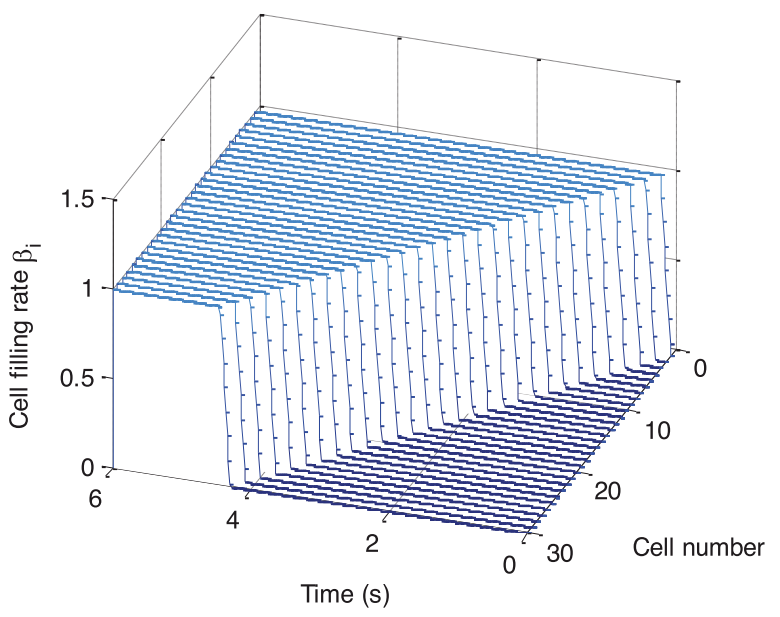

Figure 10. Filling phase of the reactor. (a) Evolution of the filling rate of the first four cells (b) Evolution of the mass hold-up of the channel. (c) Evolution of the filling rate along the reactor for $\mathrm{N}_{\text {cells }}=30$. 
Table 5. Geometric and operation parameters of the HEX reactor

\begin{tabular}{lcc}
\hline & \multicolumn{2}{c}{ Parameters } \\
\hline Reactor length & 2.35 & $\mathrm{~m}$ \\
Channel height & $0.9 \times 10^{-3}$ & $\mathrm{~m}$ \\
Channel width & $4.2 \times 10^{-3}$ & $\mathrm{~m}$ \\
Cross-sectional area & $3.78 \times 10^{-6}$ & $\mathrm{~m}^{2}$ \\
Volume & $8.9 \times 10^{-6}$ & $\mathrm{~m}^{3}$ \\
Flow rate & 7 & $\mathrm{~kg} \mathrm{~h}^{-1}$ \\
Temperature & 293.15 & $\mathrm{~K}$ \\
Pressure & 1.51 & $\mathrm{bar}(\mathrm{g})$
\end{tabular}

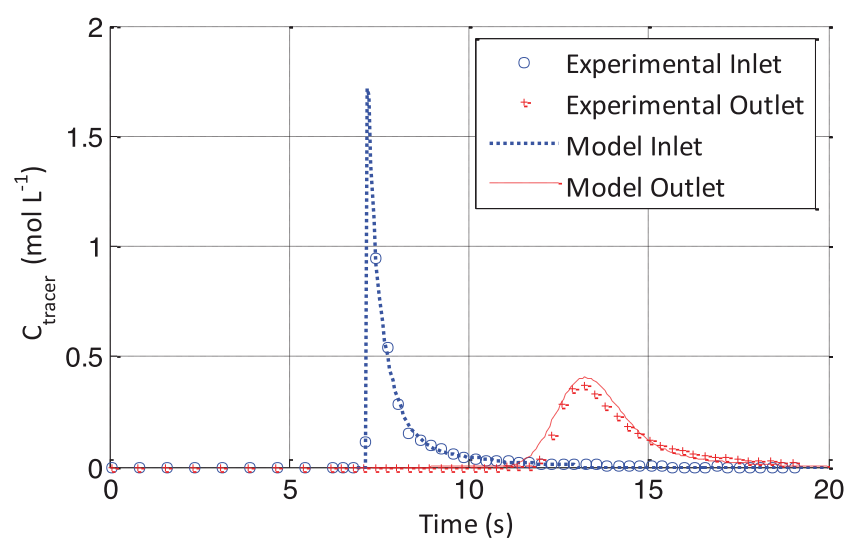

Figure 11. Residence time distribution of a HEX reactor.

\section{Case 4: Heating With a constant Temperature Wall}

Table 7 gives the geometric reactor characteristics. The simulation has been conducted with $N_{\text {cells }}=101$. The axial dispersion coefficient is set to $0.0243 \mathrm{~m}^{2} \mathrm{~s}^{-1}(\mathrm{Pe}=100)$. At $t=1 \mathrm{~s}$ transition $\mathbf{t}_{\mathbf{1}}$ is fired and wall temperature is artificially increased to generate spatial gradients of the fluid temperature. Figure 13 shows that temperature profile evolves as soon as the wall temperature increases. The discontinuity between the first node and the inlet

\section{Table 6. Operating conditions}

\begin{tabular}{lcc}
\hline $\begin{array}{l}\text { Characteristics } \\
\text { of the feed }\end{array}$ & $\begin{array}{c}\text { Conditions } \\
\text { for } \mathrm{t}<2 \mathrm{~s}\end{array}$ & $\begin{array}{c}\text { Conditions } \\
\text { for } \mathrm{t}<2 \mathrm{~s}\end{array}$ \\
\hline$x_{A}=$ Water & 1 & 0 \\
$x_{B}=$ ethanol & 0 & 1 \\
Density $\left(\mathrm{kg} \mathrm{m}^{-3}\right)$ & 995 & 785 \\
Temperature $(\mathrm{K})$ & 293.15 & 293.15 \\
Mass flow rate $\left(\mathrm{kg} \mathrm{h}^{-1}\right)$ & 5.5 & 5.5
\end{tabular}

fluid temperature is due to the choice of a "closed to dispersion" boundary condition at the inlet of the reactor (see the second section).

Steady state temperature profile is presented in Figure 14 . The fluid temperature reaches the wall temperature at $\mathrm{z} / \mathrm{L}=0.05$. This result is in agreement with the experimental behaviour of HEX reactor as reported Théron et al. ${ }^{[23]}$

\section{Case 5: Exothermic Reaction in an Adiabatic Reactor}

The reaction of sodium thiosulfate with hydrogen peroxide has been considered. This reaction, conducted in liquid solution, is very fast and strongly exothermic.

$2 \mathrm{Na}_{2} \mathrm{~S}_{2} \mathrm{O}_{3}+4 \mathrm{H}_{2} \mathrm{O}_{2} \rightarrow \mathrm{Na}_{2} \mathrm{~S}_{3} \mathrm{O}_{6}+\mathrm{Na}_{2} \mathrm{SO}_{4}+4 \mathrm{H}_{2} \mathrm{O}$

The thermokinetics parameters have been well-studied, and experimental data is available from literature. ${ }^{[21]}$ The reaction is first order in both reactants. There could be safety problems related to the evacuation of heat released by the reaction. This reaction has

\begin{tabular}{|lll|}
\hline \multicolumn{3}{l|}{ Table 7. Reactor geometric data } \\
\hline \multicolumn{3}{c}{ Reactor and parameters } \\
\hline Channel length & 7 & $\mathrm{~m}$ \\
Cross-sectional area & $4 \times 10^{-6}$ & $\mathrm{~m}^{2}$ \\
Specific heat exchange area & $2 \times 10^{3}$ & $\mathrm{~m}^{2} \mathrm{~m}^{-3}$ \\
Heat transfer coefficient & 4.5 & $\mathrm{~kW} \mathrm{~m}^{-2} \mathrm{~K}^{-1}$ \\
\hline
\end{tabular}
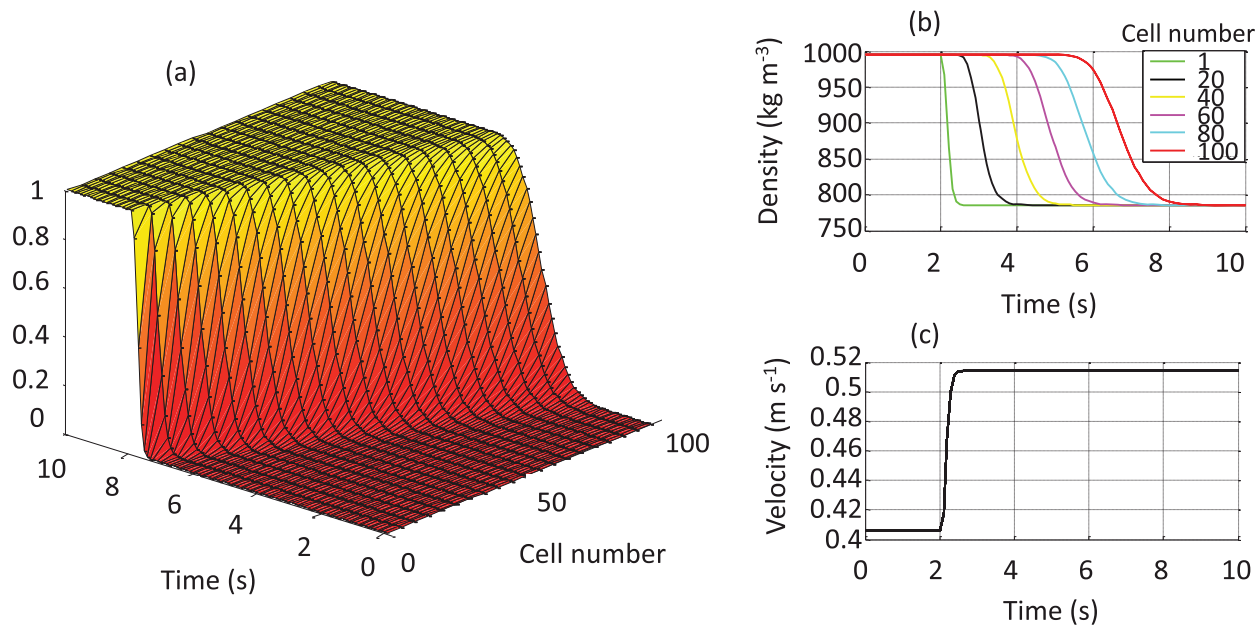

Figure 12. Filling phase of the reactor. (a) Evolution of the filling rate of the first four cells (b) Evolution of the mass hold-up of the channel. (c) Evolution of the filling rate along the reactor. 


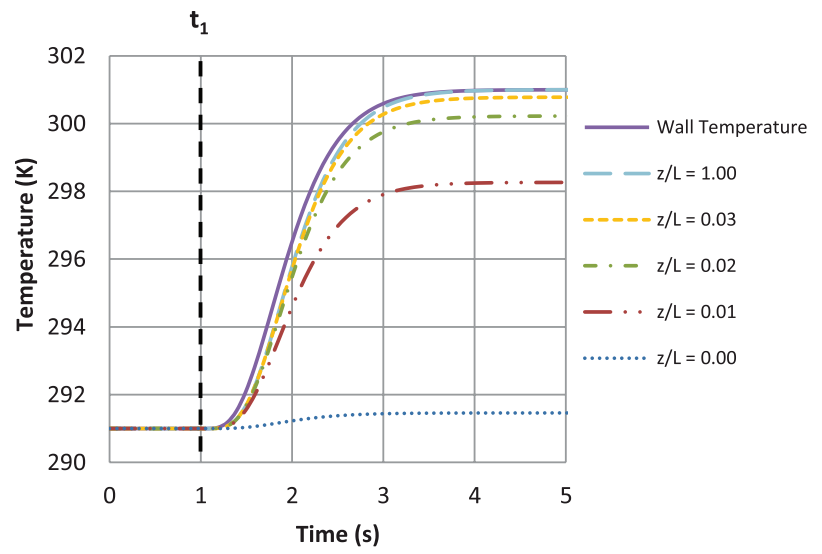

Figure 13. Dynamic behaviour of the fluid temperature during the wall temperature change.

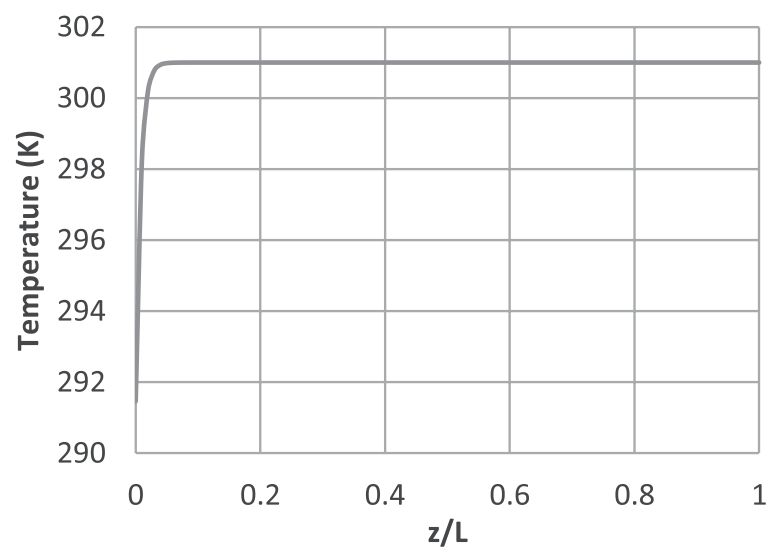

Figure 14. Steady state temperature profile after a wall temperature change.

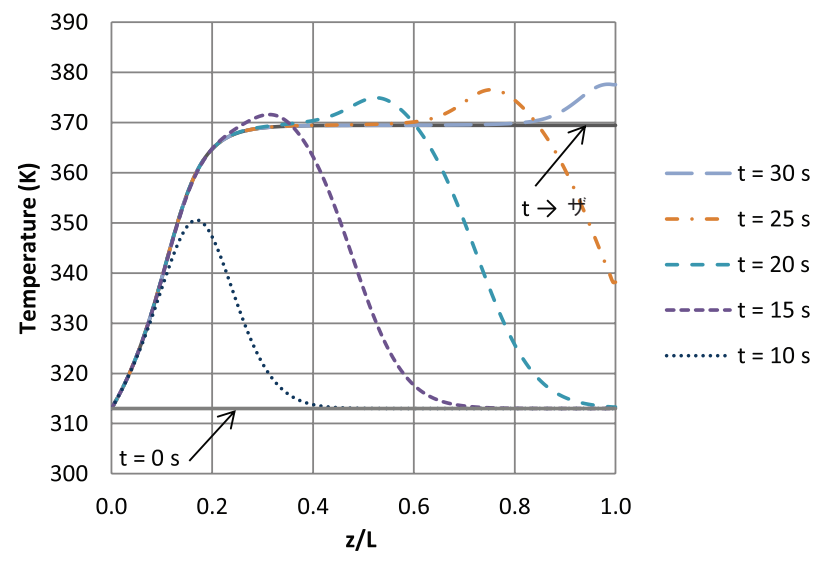

Figure 15. Temperature profile evolution for the oxidation of $\mathrm{Na}_{2} \mathrm{~S}_{2} \mathrm{O}_{3}$ carried out in an adiabatic axially-dispersed reactor.

Table 8. Thermo kinetic data.

\begin{tabular}{lll}
\hline \multicolumn{3}{c}{ Reaction kinetics } \\
\hline$E_{A r}$ & 68.20 & $\mathrm{~kJ} \mathrm{~mol}^{-1}$ \\
$k_{\text {or }}$ & $2.13 \times 10^{7}$ & $\mathrm{~m}^{3} \mathrm{~mol}^{-1} \mathrm{~s}^{-1}$ \\
$\Delta H_{r}$ & -585.8 & $\mathrm{~kJ} \mathrm{~mol}^{-1}$ of Na $\mathrm{Na}_{2} \mathrm{O}_{3}$ \\
\hline
\end{tabular}

Table 9. Inlet flow data for simulation of cases 5 and 6

\begin{tabular}{lc}
\hline \multicolumn{2}{c}{ Inlet flow properties } \\
\hline Inlet flow A \\
Flow rate \\
Composition (wt. \%) \\
Temperature & $3.3 \mathrm{~L} \mathrm{~h}^{-1}$ \\
Inlet flow B & $9 \% \mathrm{Na}_{2} \mathrm{~S}_{2} \mathrm{O}_{3}$ \\
Flow rate & $91 \% \mathrm{H}_{2} \mathrm{O}$ \\
Composition (wt. \%) & $291 \mathrm{~K}$ \\
& \\
Temperature & $1.7 \mathrm{Lh}^{-1}$ \\
\end{tabular}

been treated in safety studies as it constitutes a fast reaction system that can be operated experimentally in a continuous reactor presenting short residence time. ${ }^{[2,22]}$ The reaction rate is calculated as follows:

$R=k_{0_{r}} \cdot \exp \left(-\frac{E_{A_{r}}}{\hat{R} T}\right)\left[\mathrm{Na}_{2} \mathrm{~S}_{2} \mathrm{O}_{3}\right]\left[\mathrm{H}_{2} \mathrm{O}_{2}\right]$

Thermo kinetic data are presented in Table 8. The characteristics of the reactor are listed in Table 7. Liquid densities and specific heats of the two inlet solutions are assumed constant and equal to those of pure water as the solutions are diluted (Table 9).

The simulation was carried out with $\mathrm{N}_{\text {cells }}=201$. The axial dispersion coefficient is set to $0.0243 \mathrm{~m}^{2} \mathrm{~s}^{-1}(\mathrm{Pe}=100)$. The reactor is initialized filled with a solution of $9 \%$ of sodium thiosulfate. The inlet flow properties are presented in Table 9 . At $\mathrm{t}_{0}$ the inlet consists of inlet flow rate $\mathrm{A}$, at $3.3 \mathrm{Lh}^{-1}$. At $t=1 \mathrm{~s}$, inlet flow B is injected at a rate of $1.7 \mathrm{Lh}^{-1}$. Under these conditions the residence time is of $20 \mathrm{~s}$. Figure 15 shows the temperature profile in the reactor obtained in adiabatic mode. The heat released by the reaction increases the fluid temperature gradually from the inlet temperature to form the state profile. The heat generated by the reaction is absorbed by the fluid. At $t=35 \mathrm{~s}$ the reactor reaches steady state profile.

The conversion achieved under these conditions, which is calculated in terms of the limiting reactant (Sodium thiosulfate), is $100 \%$. The fluid temperature gradient between the inlet and the outlet of the reactor is $56.4{ }^{\circ} \mathrm{C}$.

Case 6: Exothermic Reaction With Heat Exchange With a Constant Wall Temperature

An exothermic chemical reaction is conducted in the reacting channel at a constant wall temperature $(313 \mathrm{~K})$. The simulation data is given in Tables 7, 8 and 9.

Petri net (Figure 16) represents the recipe of this simulation case:

- At $t=0 \mathrm{~s}$, the reactor is full of the fluid A.

- At $t=1 \mathrm{~s}$, transition $\mathbf{t}_{1}$ is fired and the wall temperature is increased from $292 \mathrm{~K}$ to $313 \mathrm{~K}$. The steady state is reached at $t=15 \mathrm{~s}$ (Figure 17a).

- At $t=20 \mathrm{~s}$, transition $t_{2}$ is fired. The second inlet flow can be introduced and the reaction starts.

- At $t=50 \mathrm{~s}$, the simulation ends.

The evolutions of the inlet flow rate and concentration are shown in Figure 17b-c. Figure 18 represents the temperature profile between $0 \mathrm{~s}$ and $20 \mathrm{~s}$. At this stage, the transient temperature profiles, and initial and final steady states are presented in 


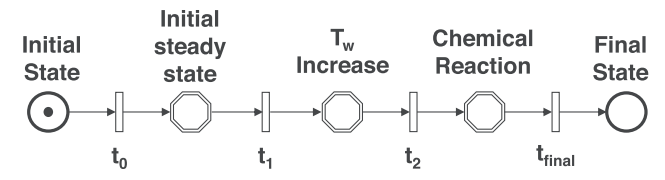

Figure 16. Recipe Petri net of the simulation of the exothermic reaction with heat exchange with a constant wall temperature.

Figure 18. The fluid temperature reaches the wall temperature at $\mathrm{z} / \mathrm{L}=0.11$.

The fluid temperature increases because of the heat released by the reaction. The steady state is reached at $t=50 \mathrm{~s}$. The maximum temperature of $315 \mathrm{~K}$ is obtained for $\mathrm{z} / \mathrm{L}=0.09$ (Figure 19). The outlet conversion at steady state is $79.1 \%$. The results are in agreement with those presented by Théron et al., ${ }^{[23]}$ who obtained a conversion of $82 \%$ under these conditions.

\section{CONCLUSION AND PERSPECTIVES}

In this paper, the dynamic modelling of a HEX reactor is discussed. The proposed model is based on the axially dispersed plug flow

(a)

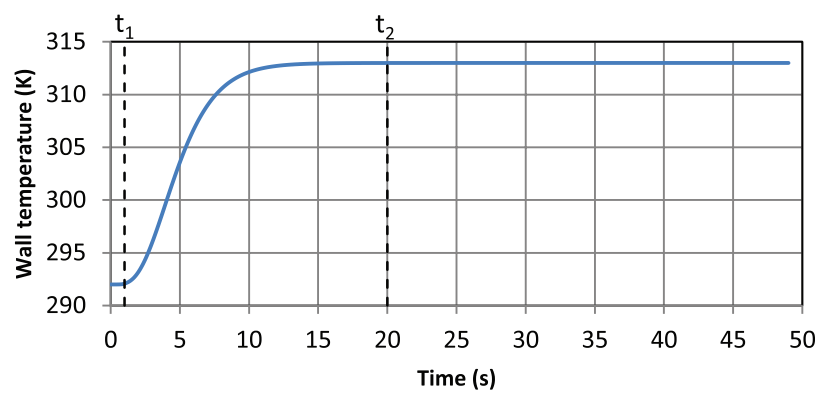

(b)

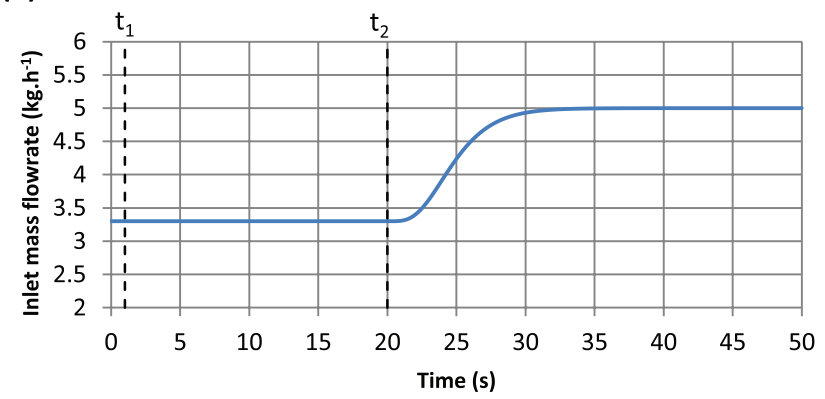

(c)

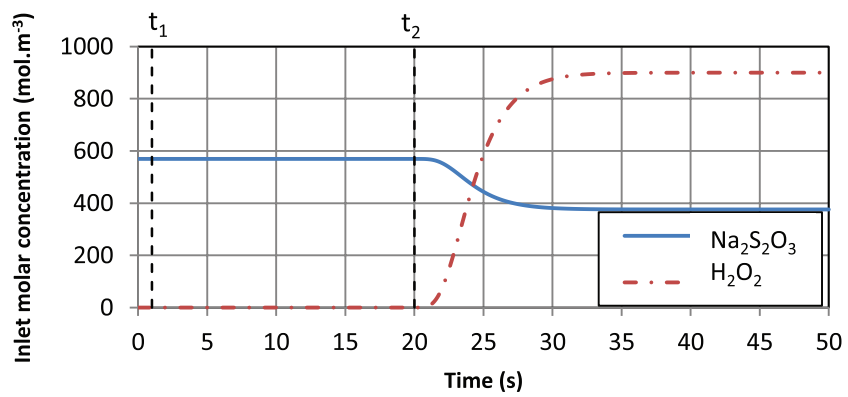

Figure 17. Fluctuations of the inlet variables. (a) Smooth step change of wall temperature (b) Evolution of the inlet mass flow rate (c) Evolution of the inlet molar concentration.

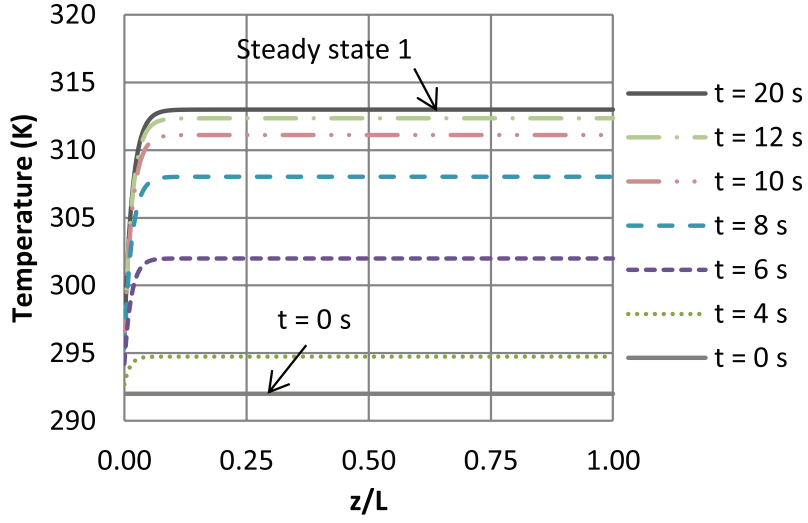

Figure 18. Transient temperature profiles between $0 \mathrm{~s}$ and $20 \mathrm{~s}$.

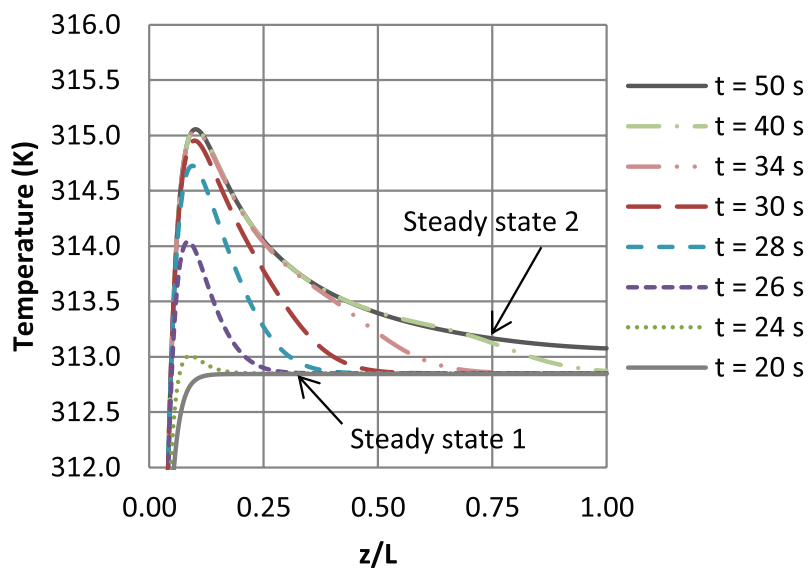

Figure 19. Transient temperature profiles between $20 \mathrm{~s}$ and $50 \mathrm{~s}$.

reactor model by taking into account the axial dispersion effects due to the non-uniformity of the reacting channel geometry. The channel is composed of a series of independent cells, linked by fluxes of mass and heat. This approach differs from the classical CSTR cascade, as it allows an independent choice of the dispersion on the hydrodynamic model and the grid definition.

The overall reactor representation can be classified as a hybrid dynamic model. Petri Nets are used to represent it. Thanks to the Petri Net formalism used, the model can be simplified and its complexity can be treated in a staged manner. The transitions between different models are easily managed. Current work is willing to integrate this model within the hybrid dynamic simulation environment PrODHys. ${ }^{[16]}$ The main advantages of the object-oriented approach rely on software quality (reusability, maintainability and extensibility), as well as on modelling thanks to the abstract hierarchical description of real systems. ${ }^{[16,25]}$

The resulting simulation tool will be useful in the definition of optimal operating conditions, to analyze the process risks in order to confirm their inherently safer characteristics and to facilitate the industrialization process. In addition to the simulation of normal operation, for a quantitative risk assessment study, the final model will also allow to take into account failure mode mechanisms.

\section{NOMENCLATURE}

a Specific heat exchange surface $\left[\mathrm{m}^{2} \cdot \mathrm{m}^{-3}\right]$

C Molar concentration $\left[\mathrm{mol} \mathrm{m}^{-3}\right.$ ] 
$C_{p} \quad$ Heat capacity $\left[\mathrm{J} \cdot \mathrm{mol}^{-1} \mathrm{~K}^{-1}\right]$

$D_{a x} \quad$ Axial dispersion coefficient $\left[\mathrm{m}^{2} \mathrm{~s}^{-1}\right]$

$\tilde{D}_{z} \quad$ Differentiation matrix for first order derivative approximation $\left[\mathrm{m}^{-1}\right]$

$\mathrm{E}_{\mathrm{A}} \quad$ Energy of activation $\left[\mathrm{J} \cdot \mathrm{mol}^{-1}\right]$

$F \quad$ Molar flow rate $\left[\mathrm{mol} \mathrm{s}^{-1}\right]$

$f_{i \pm 1 / 2}$ Molar flux $\left[\mathrm{mol} \cdot \mathrm{m}^{-2} \mathrm{~s}^{-1}\right]$

$H \quad$ Enthalpy of the system $[\mathrm{J}]$

$\Delta H \quad$ Enthalpy of reaction $\left[\mathrm{J} \mathrm{mol}^{-1}\right]$

$\mathscr{H}_{\mathrm{M}} \quad$ Term of molar production by chemical reactions [mol $\mathrm{m}^{-3} \mathrm{~s}^{-1}$ ]

$\mathscr{H}_{T} \quad$ Term of heat production by chemical reactions $\left[\mathrm{J} \mathrm{m}^{-3}\right.$ $\mathrm{s}^{-1}$ ]

$k_{o} \quad$ Pre-exponential factor $\left[\mathrm{m}^{3} \mathrm{~mol}^{-1} \mathrm{~s}^{-1}\right.$ ]

$L \quad$ Reactor length

M Reactor model

$N_{\text {cells }} \quad$ Total number of cells within a plate

$N_{\text {comp }} \quad$ Total number of chemical species

$N_{p} \quad$ Total number of reacting plates within the HEX reactor

$N_{r} \quad$ Total number of chemical reactions considered within a phase

$N_{\phi} \quad$ Total number of phases within the reactor

p Petri net place

$P \quad$ Pressure [Pa]

P Reactor plate

Pe Péclet number

$q \quad$ Discrete state

$Q_{M} \quad$ Term of mass transfer between phases $\left[\mathrm{mol} \mathrm{m}^{-3} \mathrm{~s}^{-1}\right.$ ]

$\mathrm{Q}_{T} \quad$ Term of heat transfer through the channel wall $\left[\mathrm{J} \mathrm{m}^{-3}\right.$ $\mathrm{s}^{-1}$ ]

$Q_{k}^{(\gamma \alpha)} \quad$ Mass transfer of component k from phase $\gamma$ to phase $\alpha$ $\left[\mathrm{mol} \mathrm{m}^{-3} \mathrm{~s}^{-1}\right.$ ]

$\hat{R} \quad$ Universal gas constant

$R_{k, r} \quad$ Production/consumption of component $k$ by reaction $r$ $\left[\mathrm{mol} \mathrm{m}^{-3} \mathrm{~s}^{-1}\right.$ ]

System output

System

Temperature $[\mathrm{K}]$

Velocity $\left[\mathrm{m} \mathrm{s}^{-1}\right]$

System input variable

Input variables state space

Time, independent variable [s]

Transition between two places of a petri net.

Cell volume $\left[\mathrm{m}^{3}\right]$

Molar fraction

State of a system

Continuous variables

Spatial variable $[\mathrm{m}]$

\section{Greek letters}

$\beta \quad$ Filling rate, or occupied volume fraction of each cell

Phase volume fraction

Undefined variable

Effective axial thermal conductivity $\left[\mathrm{W} \mathrm{m}^{-1} \mathrm{~K}^{-1}\right.$ ]

Stoechiometric coefficients

$\Omega \quad$ Channel cross section area $\left[\mathrm{m}^{2}\right]$

\section{Indexes}

$\alpha \quad$ Phase index

$\gamma \quad$ Phase index c Piecewise continuous or discontinuous system

d Discrete system

feed Feed flow property

$i \quad$ Discretized cell and intercell flux index

in Entering the control volume

$k \quad$ Component index

out Leaving the control volume

$u \quad$ Utility flow property

$r \quad$ Reaction index

\section{ACKNOWLEDGEMENTS}

This research work is supported by the French National Research Agency (ANR), in the framework of the PolySafe project (ANR2012-CDII-0007-01).

\section{REFERENCES}

[1] Z. Anxionnaz, M. Cabassud, C. Gourdon, P. Tochon, Chem. Eng. Process. Process Intensif. 2008, 47, 2029.

[2] W. Benaissa, S. Elgue, N. Gabas, M. Cabassud, D. Carson, M. Demissy, Int. J. Chem. React. Eng. 2008, 6, 1.

[3] S. Haugwitz, P. Hagander, T. Norén, Control Eng. Pract. 2007, 15, 779.

[4] N. Niedbalski, D. Johnson, S. S. Patnaik, D. Banerjee, Int. J. Heat Mass Transfer 2014, 70, 1086.

[5] R. Ball, B. F. Gray, Environ. Prot. 2013, 91, 221.

[6] S. Bahroun, S. Li, C. Jallut, C. Valentin, F. D. Panthou, J. Process Control 2010, 20, 664.

[7] L. Despènes, S. Elgue, C. Gourdon, M. Cabassud, Chem. Eng. Process. Process Intensif. 2012, 52, 102.

[8] M. Roudet, K. Loubiere, C. Gourdon, M. Cabassud, Chem. Eng. Sci. 2011, 66, 2974.

[9] W. E. Schiesser, The numerical method of lines, Academic Press, San Diego 1991.

[10] L. F. Shampine, M. W. Reichelt, SIAM J. Sci. Comput. 1997, $18,1$.

[11] L. F. Shampine, M. W. Reichelt, J. A. Kierzenka, SIAM Rev. $1999,41,538$.

[12] A. Vande Wouwer, P. Saucez, W. E. Schiesser, Ind. Eng. Chem. Res. 2004, 43, 3469.

[13] W. E. Schiesser, G. W. Griffiths, A Compendium of Partial Differential Equation Models: Method of Lines Analysis with $M a t l a b, 1$ st edition, Cambridge University Press, Cambridge 2009.

[14] A. Vande Wouwer, Adaptive Method of Lines, 1st ed., Chapman and Hall/CRC, Boca Raton, USA 2001.

[15] Z. Anxionnaz-Minvielle, M. Cabassud, C. Gourdon, P. Tochon, Chem. Eng. Process. Process Intensif. 2013, 73, 67.

[16] J. Perret, G. Hétreux, J.-M. Le Lann, Control Eng. Pract. 2004, $12,1211$.

[17] S. Haugwitz, P. Hagander, "Analysis and design of startup control of a chemical plate reactor with uncertainties; a hybrid approach," IEEE Int. Conf. Control Appl., 2007 p. 1426.

[18] S. A. Kaya, S. A. Attia, J. Raisch, "A suboptimal control strategy for the start-up of the Open Plate Reactor," Proc. 10th IEEE Int. Conf. Control Autom. Robot. Vis., Hanoi, Vietnam, 2008 p. 78. 
[19] J. Perret, G. Hétreux, J.-M. Le Lann, Rev. L'électricité L'électronique 2003, 71.

[20] M. Moreau, N. Raimondi, S. Elgue, N. Le Sauze, M. Cabassud, C. Gourdon, "Comparaison des comportements hydrodynamiques de réacteurs-échangeurs," Récents Prog. En Génie Procédés, SFGP, Lyon, France 2013.

[21] E. D. Lavric, P. Woehl, Chem. Today 2009, 27, 45.

[22] R. C. Vieira, E. C. Biscaia Jr, Comput. Chem. Eng. 2001, 25, 1299.

[23] F. Théron, Z. Anxionnaz-Minvielle, M. Cabassud, C. Gourdon, P. Tochon, Chem. Eng. Process. Process Intensif. 2014, 82, 30.

[24] L. Prat, A. Devatine, P. Cognet, M. Cabassud, C. Gourdon, S. Elgue, F. Chopard, Chem. Eng. Technol. 2005, 28, 1028.

[25] G. Hétreux, R. Théry, N. Olivier, J.-M. Le Lann, J. Eur. Systèmes Autom. 2007, 41, 585. 